\title{
Komatsuna Seed Extracts Protection Against Amyloid $\beta$ (1-42)-Induced Neuronal Cell Death
}

\author{
Yoshinori Okada ${ }^{1 *}$ and Mizue Okada ${ }^{2}$ \\ ${ }^{1}$ Laboratory on Ageing \& Health Management, School of Nursing \& Health, Aichi Prefectural University, Japan \\ ${ }^{2}$ Nutrition Section, Ageing and Nutrition Research, Yms Laboratory, Japan
}

\begin{abstract}
Objective: Alzheimer's disease (AD) is receiving attention as "Type 3 diabetes" and it is evident that this neurodegenerative disease has multiple shared pathologies with diabetes mellitus. Progressive dementia, increased deposition of amyloid $\beta(A \beta)$ protein in the brain is the hallmark of $A D$. $A \beta$ leads to $A \beta$ associated Reactive Oxygen Species (ROS) production and cell death. In this study, we investigated the effects of Komatsuna Seed Extracts (KSE) on $A \beta$ (1-42)-induced neurotoxicity and on the regulation of cell death processing in hippocampus neurons $(\mathrm{HN})$.
\end{abstract}

Methods: We selected sixteen plants. We investigated the effects of plant seeds' aqueous extractson (PSAE) on $A \beta$ structure modification using SDS gel electrophoresis. The neuroprotective effects of KSE were evaluated by measuring the cell viability with a CCK-8 assay. Furthermore, we carried out an anti-glycation experiment of KSE and an anti-aggregation experiment of KSE to confirm the modification mechanism of KSE. To find the effects of KSE on $A \beta$-induced oxidative stress, we examined KSE using a 2', 7'-dichlorofluorescein diacetate assay. To further unravel the effects of KSE on A $\beta$-induced cell death, we examined the influence of KSE on glucose uptake.

Results: No bands of $A \beta$ were recognized in Komatsuna, Common bean or Qing gengcai. KSE showed enhancement of cell survival amounting to a $100 \%$ blockade of AB-induced cell death. KSE caused the decrease in BSA and lactalbumin glycation. Furthermore, intracellular ROS accumulation resulting from $A \beta$ treatment was reduced when cells were treated with KSE. KSE improves glucose uptake by $A \beta$ in HN.

Conclusion: KSE inhibits $A \beta$-induced cell death. KSE reduces the toxicity of $A \beta$ by modifying $A \beta$. KSE improves the inhibition of $A \beta$ glucose uptake thereby modifying $A \beta$. KSE inhibits ROS in cells produced by $A \beta$. The possibility that KSE protects cells was suggested by these results.

Keywords: Komatsuna seed; Amyloid $\beta$; Glycation; Aggregation; Oxidative stress; Hippocampus neurons; Glucose uptake; Cell death

\section{Introduction}

At present, Alzheimer's disease (AD) is receiving attention as a "Type 3 diabetes" or "Diabetes of the brain" and it is now evident that this neurodegenerative disease has multiple shared pathologies with Diabetes Mellitus (DM) [1]. In fact, emerging evidence indicates a causal link between diabetes and AD. People with diabetes are $>1.5$ fold more likely to develop AD [2]. Namely, the prevalence of AD is higher among type 2 diabetes mellitus (T2DM) patients. In T2DM patients, the progression of $\mathrm{AD}$ is more rapid. Furthermore, $\mathrm{AD}$ and T2DM have several pathophysiological pathways in common [3]. Progressive dementia, increased deposition of Amyloid $\beta$ (A $\beta$ ) protein, neurofibrillary tangles and neuritic plaques in the brain are some of the hallmarks of AD. A greater understanding of the disease at the molecular level will enable identification of the possible targets for intervention and pave the way for either development of novel or modification of the existing therapeutic options.

Amyloid formation is implicated in more than 20 human diseases, yet the mechanism by which fibrils form is not well understood. Experimentally, a significant increase in $A \beta$ levels was observed in the cortex and hippocampus of Type 2 diabetes mice [4]. The major component of neuritic plaques is $A \beta$, a $40-42$ amino acid proteolytic fragment of the amyloid precursor protein (APP) [1]. Molecular genetic studies have linked APP mutations to some inherited forms of $\mathrm{AD}$ [5]; an alteration in the proteolytic processing of APP results in increased production and accumulation of $A \beta$ in the brain [6]. $A \beta$ can be neurotoxic by a mechanism linked to peptide fibril formation. The mechanism by which $A \beta$ produces brain dysfunction in patients with $\mathrm{AD}$ is largely unknown.

Much attention has been paid to protein glycation as a possible factor involved in protein aggregation $[7,8]$. Specifically, reducing sugar plays an important role in modifying proteins, forming advanced glycation end-products (AGEs) in a non-enzymatic process called glycation. Recent studies have shown that glycation with D-ribose induced Bovine Serum Albumin (BSA) aggregates into globular amyloid-like deposits. The amyloid-like aggregation of glycated BSA induces apoptosis in the neurotypic cell. Glycation with D-ribose induces BSA to misfold rapidly and form globular amyloid-like aggregations which play an important role in cytotoxicity to neural cells [9]. In addition, glycation of $A \beta$ markedly enhances its aggregation in vitro, and the glycation of tau, in addition to hyperphosphorylation, appears to enhance the formation of paired helical filaments [10]. To this concern, in the present study we have investigated the effect of glycation on the aggregation pathways of

*Corresponding author: Yoshinori Okada, Laboratory on Ageing \& Health Management, School of Nursing \& Health, Aichi Prefectural University, Tohgoku, Kamishidami, Moriyama, Nagoya, 463-8502, Japan, Tel: +81-52-736-1401; Fax +81-52-736-1415; E-mail: yolage@nrs.aichi-pu.ac.jp

Received March 30, 2014; Accepted May 08, 2014; Published May 13, 2014

Citation: Okada Y, Okada M (2014) Komatsuna Seed Extracts Protection Against Amyloid $\beta(1-42)-$ Induced Neuronal Cell Death. J Diabetes Metab 5: 368 doi:10.4172/2155-6156.1000368

Copyright: $(2014$ Okada Y, et al. This is an open-access article distributed under the terms of the Creative Commons Attribution License, which permits unrestricted use, distribution, and reproduction in any medium, provided the original author and source are credited. 
BSA and Lactalbumin (LAB). Although this reaction may not be related to a direct amyloid disease, it is thought to be a good representative model of proteins that intrinsically evolve toward the formation of amyloid aggregates. Iannuzzi et al. [11] showed that AGE formation strongly accelerates amyloid fibrilformation. Therefore, we examined the influence of Komatsuna Seed Extracts (KSE) on this reaction.

Hypometabolism of the posterior cingulate cortex (PCC) in early $\mathrm{AD}$ is thought to arise in part due to $\mathrm{AD}$-specific neuronal damage to the hippocampal formation. Yakushev et al. [12] found an inverse association between anterior hippocampal diffusivity and PCC glucose metabolism, which was in turn strongly related to episodic memory performance in subjects with early AD. Studies of animal and cell culture models of $\mathrm{AD}$ suggest that increased levels of oxidative stress (membrane lipid peroxidation, in particular) may disrupt neuronal energy metabolism and ion homeostasis, by impairing the function of membrane ion-motive ATPases and glucose transporters [13]. The overproduction of $A \beta$ leads to $A \beta$ associated ROS production and cell death. In addition, experimental evidence on this accumulation suggests links between deposition of $\mathrm{A} \beta$, oxidative stress, and apoptosis associated with $\mathrm{AD}[14,15]$. Although the mechanisms of neuronal cell loss in $\mathrm{AD}$ have not yet been fully revealed, increased oxidative stress is considered to be an important initiator/mediator of neuronal damage in $\mathrm{AD}$ [16]. Not only does $\mathrm{A} \beta$ increase oxidative stress, but its generation is also increased as a result of oxidative stress, which in turn causes more oxidative damage.

Diets rich in plant-derived polyphenols have been shown to reduce the incidence of various diseases including $\mathrm{DM}$ and $\mathrm{AD}$. Polyphenols are thought to provide health benefits by decreasing the risk of disease. Extensive studies have been focused on the positive role of vegetable polyphenols as ROS scavengers and in disease prevention $[17,18]$. Experimental evidence indicates that polyphenols have neuroprotective effects in animals [19]. Plant seeds possess considerably stronger antioxidant activity [20].

We recently conducted a large scale screening of 15 plant seeds' aqueous extracts (PSAE) for inhibitory activity on A $\beta$ (25-35)-induced neurotoxicity in vitro [20]. The study showed that Komatsuna Seed Extracts (KSE) effectively decreased A $\beta$ (25-35)-induced neurotoxicity. Furthermore, TNF- $\alpha$ production resulting from $A \beta$ (25-35) treatment was reduced when cells were treated with KSE. Considering these findings, in the present study we investigated the effects of KSE on $\mathrm{A} \beta$ (1-42)-induced neurotoxicity and on the regulation of cell death processing in Hippocampus Neurons (HN).

\section{Materials and Methods}

\section{Reagents}

We purchased reagents from the following sources: $\mathrm{HN}(\mathrm{MB}-\mathrm{X} 0403)$, nerve cell dispersion medium set, nerve cell culture medium from DS Pharma Biomedical Co, Ltd. (Osaka, Japan); 2',7'-dichlorofluoresce in (DCF), 2',7'-Dichlorofluorescein Diacetate (DCF-DA), and bovine serum albumin from Sigma-Aldrich(St. Louis, MO, USA); Glucose Uptake Cell-Based Assay Kit from Cayman Chemical Company (Ann Arbor, MI, USA). We obtained all other analytical grade (or highest grade available) chemicals from Wako Pure Chemical Industries, Ltd. (Osaka, Japan).

\section{Preparation of aqueous extracts from plant seeds (PSAE)}

We selected sixteen plants, nine of which were medicinal plants (Japanese honeywort, Luffa, Rapeseed, Chinese colza, Potherb Mustard, Japanese radish, Bitter melon, Red Shiso, Corn and Kaiware radish) and seven which were general, commercially available plants (Common bean, Komatsuna, Qing gengcai, Bell pepper, Kale, Crown daisy and Lettuce). As the seeds are sowed and cultivated in Japan in spring through summer, sixteen plant seeds were collected from a market in Japan. Dried plant seeds were ground to fine powder with a grinder (LaboMilser LM-PLUS, Osaka Chemical Co., Ltd.). Ten times distilled water of volume of the seed powder was added to each powdered seed containing tube. The tubes were quickly immersed in a water bath of $95-100^{\circ} \mathrm{C}$ for $10 \mathrm{~min}$ and stirred for $60 \mathrm{~min}$. Each tube was then placed on ice, and the extracts were filtrated using a filter paper. The collected filtrate was then stored under $-20^{\circ} \mathrm{C}$ until use. When used in assays, each sample was returned to ambient temperature, followed by filtration through a membrane filter (pore size $0.22 \mu \mathrm{m}$ ).

\section{Measurement of SDS-polyacrylamide gel electrophoresis}

Briefly, $75 \mu \mathrm{L}$ of PSAE or PBS was combined with $75 \mu \mathrm{L}$ of A $\beta$ (142) ( $10 \mu \mathrm{M}$; Wako Pure Chemical Industries, Ltd.) solution. We allowed the mixture to sit for $1 \mathrm{~h}$ at $37^{\circ} \mathrm{C}$ before measuring SDS-polyacrylamide gel electrophoresis. Ten $\mu \mathrm{L}$ of incubated samples was mixed with $10 \mu \mathrm{L}$ of SDS-PAGE sample buffer and loaded on $15 \%$ SDS-polyacrylamide gel. The samples were electrophoresed at $40 \mathrm{~A}$ for $1 \mathrm{~h}$. The gels were stained for protein with Quick CBB PLUS (Wako co. Ltd). Molecular masses of the bands obtained were calculated with the help of the standard molecular weight markers (Precision Plus Protein ${ }^{\text {Tw }}$ Prestained Standards; Bio-Rad Laboratories), CA, USA.

\section{Cell culture}

$\mathrm{HN}$ was cultured for 7 days in a 96-well plate in nerve cell culture medium and was maintained at $37^{\circ} \mathrm{C}$ in a $5 \% \mathrm{CO}_{2}$ incubator. On day 7 or after the preculture of cells, KSE (up to $50 \mu \mathrm{L}$ ) was added to the culture medium. Cells were grown for $1 \mathrm{~h}$ under $5 \% \mathrm{CO}_{2}$ at $37^{\circ} \mathrm{C}$. Then, the cells were further cultured in 96-well plates in mediums with or without $A \beta(1-42)$ for $48 \mathrm{~h}$.

\section{Assessment of cell viability}

HN were seeded on a 96-well plate in nerve cell culture medium $(100 \mu \mathrm{L})$ at a concentration of $2.6 \times 10^{4}$ cells per well and either exposed or not exposed to KSE for $1 \mathrm{~h}$. The cells were then exposed to $10 \mu \mathrm{M}$ A $\beta$ (1-42) for $48 \mathrm{~h}$. After $48 \mathrm{~h}$ incubation, a $10 \mu \mathrm{L}$ Cell Counting Kit8 (CCK-8; Dojindo Molecular Technologies, Inc., Japan) solution was added and culturing continued for $1 \mathrm{~h}$ under $5 \% \mathrm{CO}_{2}$ at $37^{\circ} \mathrm{C}$. The cell count was measured $\mathrm{A}_{450 \mathrm{~nm}}$. Cell viability (\%) was expressed as a percentage of the untreated control as follows: $\%$ cell viability $=\left(A_{450 \mathrm{~nm}}\right.$ of treated cells/ $\mathrm{A}_{450 \mathrm{~nm}}$ of untreated cells) $\times 100$

\section{In vitro glycation of Bovine Serum Albumin (BSA) and Lactalbumin (LAB) induced by $D$-ribose}

After sterilization, using a Millex GV filter (Millipore, Cork, Ireland) to prevent bacterial growth, BSA and LAB were dissolved in 20 $\mathrm{mM}$ Tris- $\mathrm{HCl}$ ( $\mathrm{pH} 7.4$ ) to yield a stock solution of $20 \mathrm{mg} / \mathrm{mL}$ D-ribose (1M; a final concentration) was then prepared in Tris- $\mathrm{HCl}$ to final concentrations of $10 \mathrm{mg} / \mathrm{mL}$ BSA or LAB. KSE ( 4 or $8 \mu \mathrm{L})$ were added to $20 \mathrm{mM}$ Tris- $\mathrm{HCl}$ containing $1 \mathrm{M}$ D-ribose and either BSA $(167 \mu \mathrm{L})$ or LAB $(167 \mu \mathrm{L})$ to acquire final concentrations of $10 \mathrm{mg} / \mathrm{ml}$. Then, the solutions were incubated at $37^{\circ} \mathrm{C}$ for up to 10 days. After incubation, the fluorescent reaction products were assayed on a fluorophotometer ( $\lambda$ ex360 nm/גem465 nm; multimode microplate reader Infinite F200, Tecan Trading AG, Switzerland) [9]. BSA or LAB in the presence of D-ribose was used as a control. Each experimental condition was performed in triplicate. 
Citation: Okada Y, Okada M (2014) Komatsuna Seed Extracts Protection Against Amyloid B(1-42)-Induced Neuronal Cell Death. J Diabetes Metab 5: 368 doi:10.4172/2155-6156.1000368

Page 3 of 8

\section{In vitro aggregation of $\mathrm{BSA}$ and $\mathrm{LAB}$ induced by $\mathrm{D}$-ribose}

KSE ( 4 or $8 \mu \mathrm{L}$ ) was added to $20 \mathrm{mM}$ Tris- $\mathrm{HCl}$ containing $1 \mathrm{M}$ (a final concentration) D-ribose and either BSA $(167 \mu \mathrm{L})$ or LAB $(167 \mu \mathrm{L})$ to acquire final concentrations of $10 \mathrm{mg} / \mathrm{ml}$. Then, the solutions were incubated at $37^{\circ} \mathrm{C}$ for up to 10 days. After incubation, thioflavin $\mathrm{T}$ (ThT, $30 \mu \mathrm{M})$, commonly used to detect protein aggregations, was added to the mixture solution to investigate whether any amyloid-like deposits formed at $37^{\circ} \mathrm{C}$. After incubation for $10 \mathrm{~min}$, the fluorescent reaction products were assayed on a fluorophotometer $(\lambda \operatorname{ex} 430 \mathrm{~nm} / \lambda$ em 465 $\mathrm{nm})$. BSA or LAB in the presence of D-ribose was used as a control. Each experimental condition was performed in triplicate.

\section{Measurement of oxidative stress}

Levels of cellular oxidative stress were measured using the DCF-DA assay. $\mathrm{HN}$ were pretreated for $1 \mathrm{~h}$ with the various concentrations (7.5 or $50 \mu \mathrm{L} \mathrm{KSE}$ ), and then exposed to $10 \mu \mathrm{M} \mathrm{A} \beta(1-42)$ for $48 \mathrm{~h}$. At the end of the treatment, the cells were incubated with $50 \mu \mathrm{M}$ DCF-DA for 30 min and DCF was quantified with a fluorometer (Infinite F200, Tecan, Switzerland) using $485 \mathrm{~nm}$ excitation and $535 \mathrm{~nm}$ emission filters. The results are given as percent relative to the oxidative stress of the control cells set to $100 \%$. DCF-DA (\%) was expressed as a percentage of the untreated control as follows: \% DCF-DA=(fluorescence intensity of treated cells/ fluorescence intensity of untreated cells $) \times 100$.

\section{Glucose Uptake Cell-Based Assay}

The Glucose Uptake Cell-based Assay Kit provides a convenient tool for studying modulators of cellular glucose uptake. The kit employs 2-NBDG, a fluorescently-labeled deoxyglucose analog, as a probe for the detection of glucose taken up by cultured cells. The detection of glucose uptake was analyzed using the fluorescence method with a commercial kit according to instructions provided by the manufacturer (Cayman Chemical, MI, USA). HN were pretreated for $1 \mathrm{~h}$ with the various concentrations ( 7.5 or $50 \mu \mathrm{L} \mathrm{KSE}$ ), and then exposed to $10 \mu \mathrm{M} \mathrm{A} \beta$ (1-42). After treatments, cultures were maintained at $37^{\circ} \mathrm{C}$ for $48 \mathrm{~h}$. Before the addition of 2-NBDG treatments, the cultures were switched to glucose-free culture medium containing 2-NBDG. The assay was stopped $1 \mathrm{~h}$ later by aspiration of the supernatant and washing with Cell-based Assay Buffer. The amount of 2-NBDG taken up by the cells was quantified with a fluorometer (Infinite F200) using $485 \mathrm{~nm}$ excitation and 535 $\mathrm{nm}$ emission filters. The results are given as percent relative to the glucose taken up by the control cells set to $100 \%$. Glucose uptake (\%) was expressed as a percentage of the untreated control as follows: \% Glucose uptake $=($ fluorescence intensity of treated cells/ fluorescence intensity of untreated cells) $\times 100$.

\section{Glucose level assay}

The BioVision Glucose Assay Kit provides direct measurement of glucose in cell culture supernatants. Glucose Enzyme Mix specifically oxidizes glucose to generate a product which reacts with a dye to generate color $\left(\mathrm{A}_{570 \mathrm{~nm}}\right)$. HN were pretreated for $1 \mathrm{~h}$ with the various concentrations ( 7.5 or $50 \mu \mathrm{L} \mathrm{KSE}$ ), and then exposed to $10 \mu \mathrm{M} \mathrm{A} \beta$ (142) for $48 \mathrm{~h}$.At the end of the treatment, the supernatant was collected and the level of glucose in the supernatant was read at $570 \mathrm{~nm}$ using a microplate spectrophotometer (Multiskan GO, Thermo Fisher Scientific, Japan). Glucose level (\%) was expressed as a percentage of the untreated control as follows:

$\%$ Glucose levels $=($ absorbance of treated cells/ absorbance of untreated cells) $\times 100$

\section{Statistical analysis}

We present all data as mean $\pm \mathrm{SD}$. The statistical comparison between the groups was carried out using either ANOVA or Students t-test. $P$ values $<0.05$ were considered statistically significant.

\section{Results}

\section{Amyloid $\beta$ electrophoretic analysis}

In the present study, we investigated the effects of PSAE on A $\beta$ structure modification. The mixture samples were electrophoresed at $40 \mathrm{~A}$ for $1 \mathrm{~h}$ (Figure 1 ). No bands of $\mathrm{A} \beta$ were recognized in Komatsuna, Common bean and Qing gengcai samples. This suggests that some special conformation, presumably in protein, was present in a major constituent of amyloid. Therefore, we carried out the following experiments involving KSE that showed that its effect was remarkable in this electrophoretic experiment.

\section{Effects of KSE on cell viability in A $\beta$ (1-42)-induced HN}

The neuroprotective effects of KSE were evaluated by CCK- 8 assay measuring cell viability in $\mathrm{A} \beta$-induced $\mathrm{HN}$ (Figure 2). Following induction of $\mathrm{A} \beta$ for $48 \mathrm{~h}$, cell survival was reduced to $84.2 \pm 4.41 \%$ compared to the control. Of KSE concentrations that were used to treat $A \beta$-induced neurons, both concentrations $(7.5$ or $50 \mu \mathrm{L})$ showed

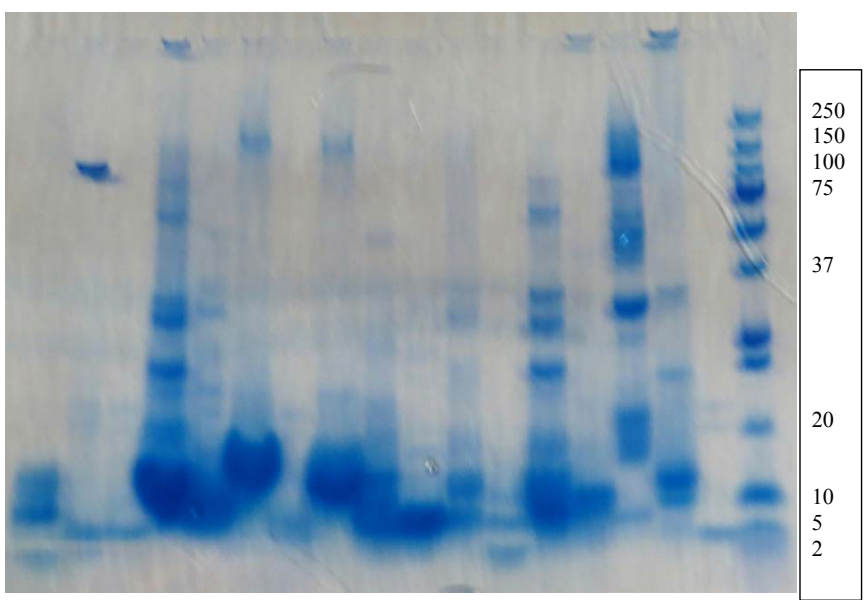

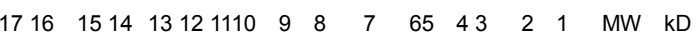

Figure 1: $15 \%$ SDS-PAGE of the products of $A \beta$ (1-42) incubation with plant seeds extracts (PSAE).

SDS-PAGE illustrating the inhibition effect of PSAE on $A \beta$ (1-42). Lanes (from right toleft) indicating the electrophoretic migration of the $A \beta(1-42)$ in the absence of PSAE; in the presence of PSAE.

1. $A \beta(1-42)$

2. Japanese honeywort (Cryptotaenia japonica Hassk.)

3. Common bean (Phaseolus vulgaris $L$.)

4. Luffa (Luffa cylindrica (L.) Roem.)

5. Rapeseed,Chinese colza (Brassica rapa L. var. nippo-oleifera)

6 Potherb Mustard (Brassica rapa L.var. nipposinica (L.H.Bailey) Kitam)

7. Japanese Radish (Raphanus sativus var. sativus)

8. Bitter melon (Momordica charantia)

9. Red Shiso (Perilla frutescens (L.) Britton var. crispa (Thunb.) H.Deane)

10. Komatsuna (Brassica rapa var. perviridis)

11. Corn (Zea mays L.)

12. Qing geng cai (Brassica rapa var. chinensis)

13. Bell pepper (Capsicum annuum L. var. 'grossum')

14. Kale (Brassica oleracea L. var. acephala DC.)

15. Crown daisy (Chrysanthemum coronarium)

16. Lettuce (Lactuca sativa L.)

17. Kaiware radish (Raphanus sativus MW shows a molecular weight marker. All tested samples were analyzed by $15 \%$ tris-HCI-SDS-PAGE, followed by Quick-CBB PLUS staining, as described in the experimental part. 


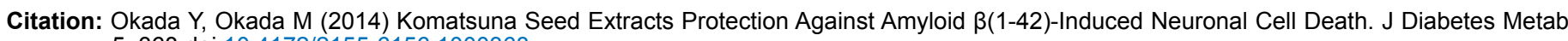
5: 368 doi:10.4172/2155-6156.1000368

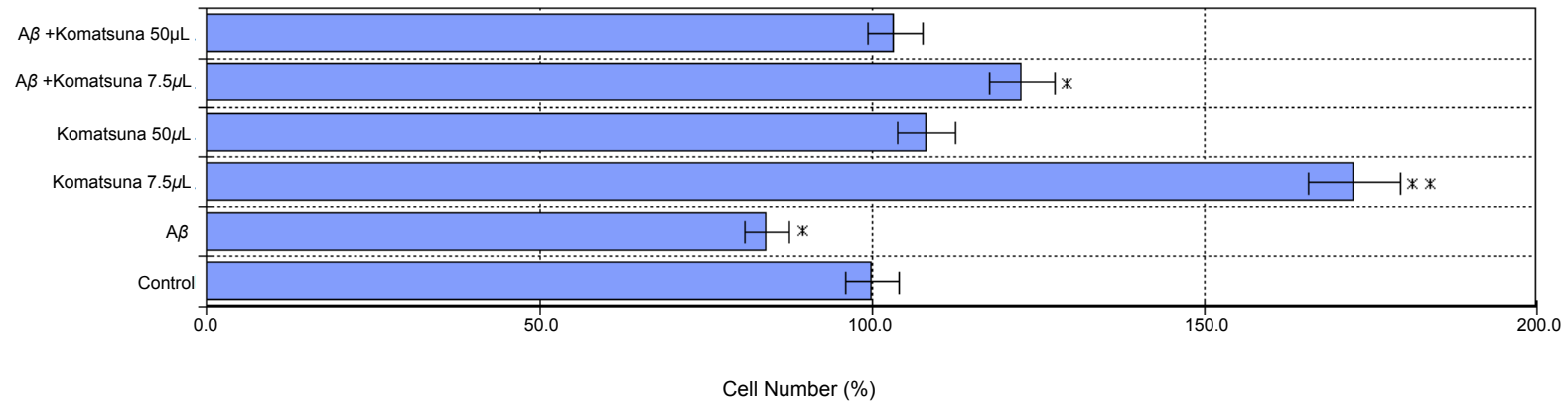

Figure 2: Cell viability measured by CCK-8 assays.

Hippocampus neurons were grown on 96 -well plates. $\mathrm{A} \beta$ alone or incubated with different concentrations of $\mathrm{KSE}(7.5$, or $50 \mu \mathrm{L})$ at $37^{\circ} \mathrm{C}$, was added to hippocampus neurons for $48 \mathrm{~h}$ and cell viability was measured using the CCK-8 assay at $1 \mathrm{~h}$. Data represents the percentage of viable cells relative to untreated cells. Values are the mean \pm SD of three measurements. ${ }^{* *} \mathrm{p}<0.01,{ }^{*} \mathrm{p}<0.05$ compared with the controls.
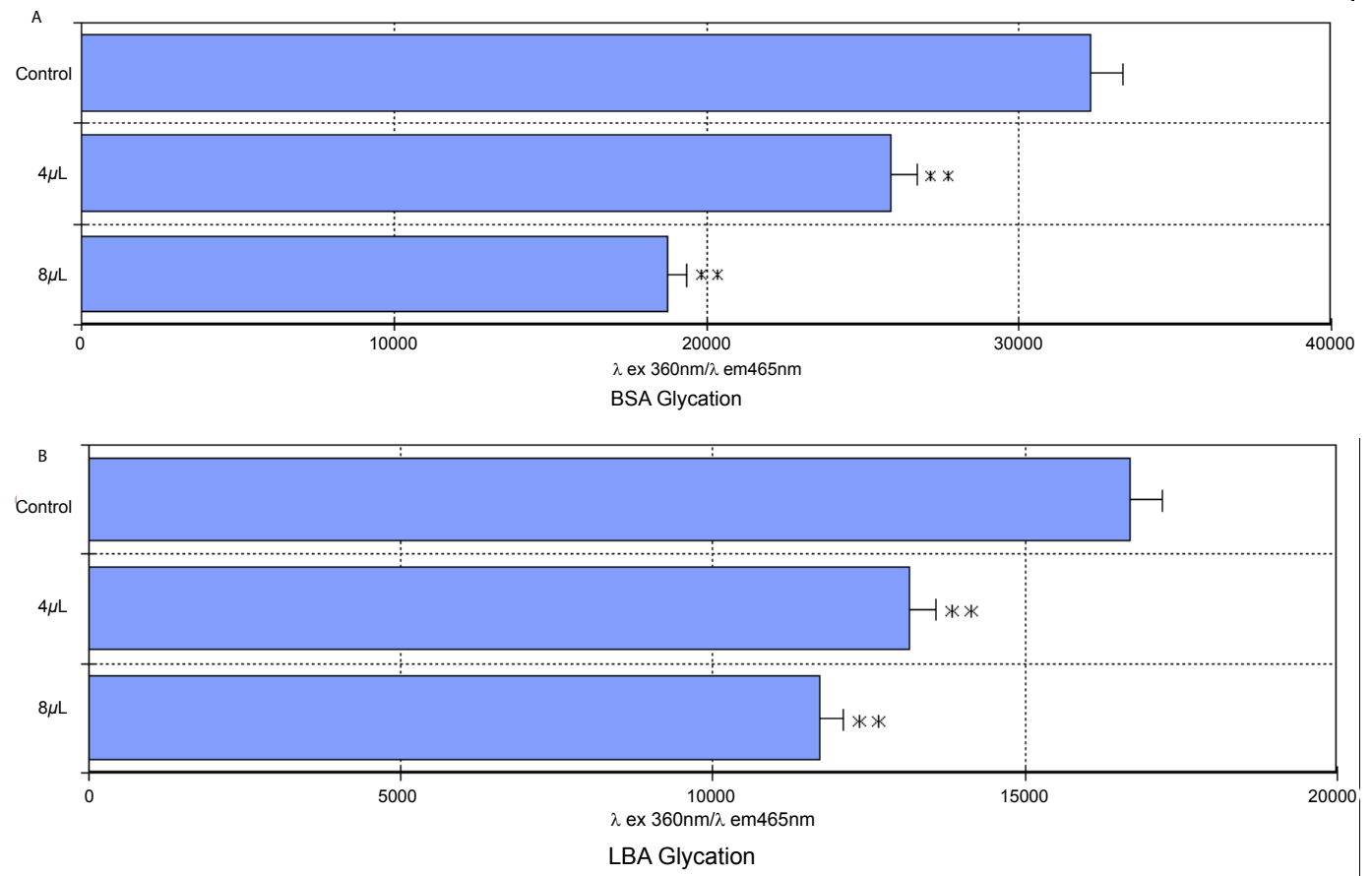

Figure 3: Changes in the fluorescence of BSA or LAB+D-ribose treated with KSE.

BSA or LAB (final concentration $10 \mathrm{mg} / \mathrm{mL}$ ) in the presence of D-ribose (final concentration $1 \mathrm{M}$ ) was kept at $37^{\circ} \mathrm{C}$ in Tris- $\mathrm{HCl}$ buffer (pH 7.4 ). $\mathrm{KSE}(4$ and $8 \mu \mathrm{L}$ ) was mixed with samples of BSA (Figure 3-a) or LAB (Figure 3-b) +D-ribose for up to 10 days. The fluorescence intensity of glycation was recorded ( $\lambda$ ex 360 nm; $\lambda$ em 465 $\mathrm{nm}$ ).BSA (or LAB) and D-ribose were used as a control. Aliquots were taken for measurements of fluorescence spectra ( $\lambda$ ex $360 \mathrm{~nm}$; $\lambda$ em $465 \mathrm{~nm}$ ). Values are the mean \pm SD of three measurements. ${ }^{* *} p<0.01$ compared with the controls.

enhancement of cell survival compared to the $A \beta$ treatment. Similarly, cell number was significantly induced when cells were treated with KSE only as compared to the control. KSE showed enhancement of cell survival, compared to that of the control level, amounting to a $100 \%$ blockade of $A \beta$-induced cell death. The degrees of cell survival ranged from $103.4 \pm 4.85 \%$ ( $\mathrm{A} \beta+$ komatsuna $50 \mu \mathrm{L}$ ) to $122.6 \pm 5.56 \%$ $(\mathrm{A} \beta+$ komatsuna $7.5 \mu \mathrm{L})$ of the control level. These results clearly demonstrate that KSE is a potent protectant against $A \beta$.

\section{Effects of KSE on glycation of BSAor LAB induced by D-ribose}

In Figure 3a, fluorescence assay results showed that BSA glycation levels significantly decreased in the 10-day KSE-loaded treatments relative to the control; inhibition of BSA glycation by 4 and $8 \mu \mathrm{L} \mathrm{KSE}$ decreased $24.2 \pm 2.68 \%$ and $38.2 \pm 1.79 \%$, respectively $(\mathrm{P}<0.01) . \mathrm{KSE}$ $(8 \mu \mathrm{L})$ caused a maximum decrease $(38.2 \pm 1.79 \%)$ in BSA glycation as determined by a concentration-dependent pilot experiment using all KSE concentrations between 0 and $8 \mu \mathrm{L}$ (Figures $3 \mathrm{a}$.).

On the other hand, fluorescence assay results (Figure $3 \mathrm{~b}$ ) showed that LAB glycation levels significantly decreased in the 10-day KSEloaded treatments relative to the control; inhibition of $\mathrm{LAB}$ glycation by 4 and $8 \mu \mathrm{L}$ KSE decreased $22.8 \pm 3.07 \%$ and $28.2 \pm 2.19 \%$, respectively $(\mathrm{P}<0.01)$. KSE $(8 \mu \mathrm{L})$ caused the maximum decrease $(28.2 \pm 2.19 \%)$ in LAB glycation as determined by a concentration-dependent pilot experiment using all KSE concentrations between 0 and $8 \mu \mathrm{L}$ (Figure 3b). 


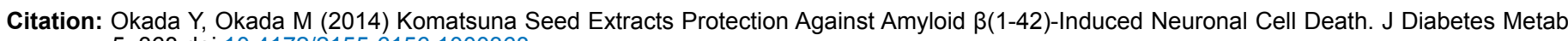
5: 368 doi:10.4172/2155-6156.1000368

Page 5 of 8
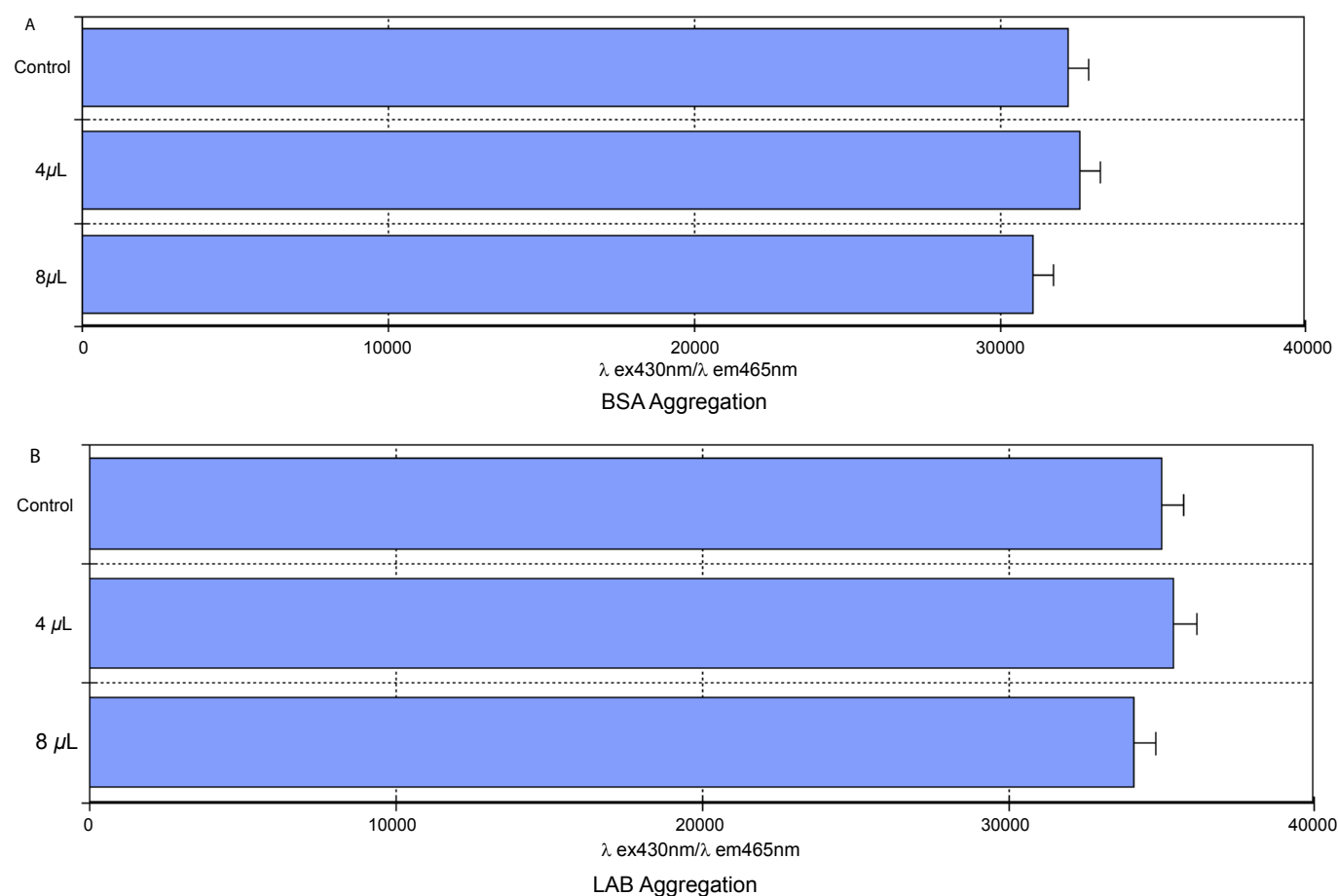

Figure 4: Changes in the Thioflavin T fluorescence of BSA or LAB+D-ribose treated with KSE.

BSA or LAB (final concentration $10 \mathrm{mg} / \mathrm{mL}$ ) in the presence of D-ribose (final concentration $1 \mathrm{M}$ ) was kept at $37^{\circ} \mathrm{C}$ in Tris- $\mathrm{HCl}$ buffer (pH 7.4 ). Thioflavin $\mathrm{T}$ (final concentration30 $\mu \mathrm{M}$ ) was mixed with samples of BSA (Figure 4-a) or LAB (Figure 4-b) +D-ribose + KSE (4 or8 $\mu \mathrm{L}$ ), as described in Materials and Methods. The fluorescence intensity of Thioflavin T was recorded ( $\lambda$ ex $430 \mathrm{~nm} ; \lambda$ em $465 \mathrm{~nm}$ ).BSA (or LAB) and D-ribose were used as a control. Aliquots were taken for measurements of fluorescence spectra $(\lambda e x=430 \mathrm{~nm})$. Values are the mean \pm SD of three measurements.

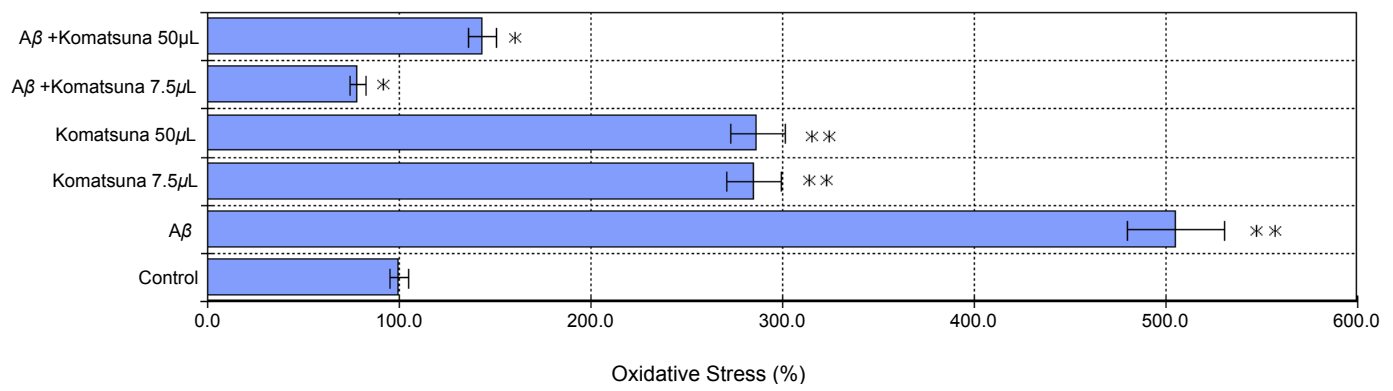

Figure 5: Effect of KSE on ROS generation in A $\beta$ (1-42)-induced neurons.

Hippocampus neurons were pretreated for $1 \mathrm{~h}$ with various concentrations ( 7.5 or $50 \mu \mathrm{L} \mathrm{KSE})$. After $1 \mathrm{~h}$, the cells were treated with $10 \mu \mathrm{M} A \beta(1-42)$ for $48 \mathrm{~h}$. The increase of DCF-DA fluorescence was measured by fluorescence microplate reader ( $\lambda$ ex $485 \mathrm{~nm} / \lambda$ em535 nm). The ROS productions of control and KSE are indicated by shaded columns. Values are the mean \pm SD of three measurements. ${ }^{* *} p<0.01,{ }^{*} p<0.05$ compared with the controls.

\section{Effects of KSE on aggregates of D-ribose-glycated BSA or LAB}

We added Thioflavin $\mathrm{T}$ (ThT, a fluorescent reagent) to test whether KSE is the inhibition of amyloid-like aggregates (Figure 4a). Fluorescence of ThT at $\lambda$ ex $430 \mathrm{~nm} / \lambda \mathrm{em} 465 \mathrm{~nm}$ significantly increased in the presence of BSA incubated with D-ribose for 10 days. Fluorescence intensity showed about $3200 \pm 74.8$ counts in BSA+D-ribose. However, $\mathrm{BSA}+\mathrm{D}$-ribose incubated with KSE (4 or $8 \mu \mathrm{L})$ showed no significant changes in ThT fluorescence under our experimental conditions.

On the other hand, we added ThT to test whether KSE is the inhibition of amyloid-like aggregates (Figure $4 \mathrm{~b}$ ). Fluorescence of ThT at $\lambda$ ex $430 \mathrm{~nm} / \lambda$ em $465 \mathrm{~nm} \mathrm{~nm}$ significantly increased in the presence of LAB incubated with D-ribose for 10 days. Fluorescence intensity showed about $3500 \pm 76.1$ counts in $\mathrm{LAB}+\mathrm{D}$-ribose. However, $\mathrm{LAB}+\mathrm{D}$ ribose incubated with KSE ( 4 or $8 \mu \mathrm{L}$ ) showed no significant changes in ThT fluorescence under our experimental conditions.

\section{KSE effects on intracellular ROS in A $\beta$ (1-42)-induced HN}

We measured levels of cellular oxidative stress using a DCF-DA assay. Exposure of $\mathrm{HN}$ to $10 \mu \mathrm{M} \mathrm{A} \beta$ for only $48 \mathrm{~h}$ resulted in a significant increase of ROS levels (Figure 5). As shown in Figure 5, HN exposed to $A \beta$ showed an oxidative stress increase of approximately 5 times that of the control. Similarly, intracellular ROS level was significantly induced when cells were treated with KSE only as compared to the 


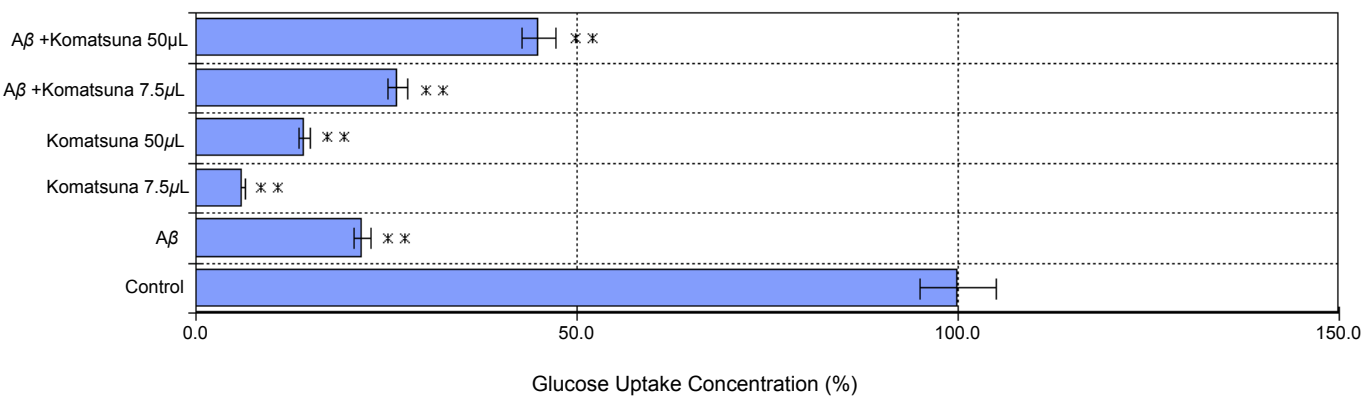

Figure 6: Effect of KSE on glucose uptake in hippocampus neurons.

Hippocampus neurons were pretreated for $1 \mathrm{~h}$ with the various concentrations (7.5 or $50 \mu \mathrm{L} K S$ ), and then exposed to $10 \mu \mathrm{M} A \beta$ (1-42). On day 2 , the $A \beta$ (1-42)-induced hippocampus neurons treated with KSE (7.5 or $50 \mu \mathrm{L})$ were exposed to 2-NBDG for $1 \mathrm{~h}$. The levels of 2-NBDG uptake were determined after the treatment, as described in Materials and Methods. The increase of 2-NBDG fluorescence was measured by fluorescence microplate reader ( $\lambda$ ex485 $\mathrm{nm} / \lambda$ em535 $\mathrm{nm}$ ). Values are the mean \pm SD of three measurements. ${ }^{* *} p<0.01$ compared with the controls.

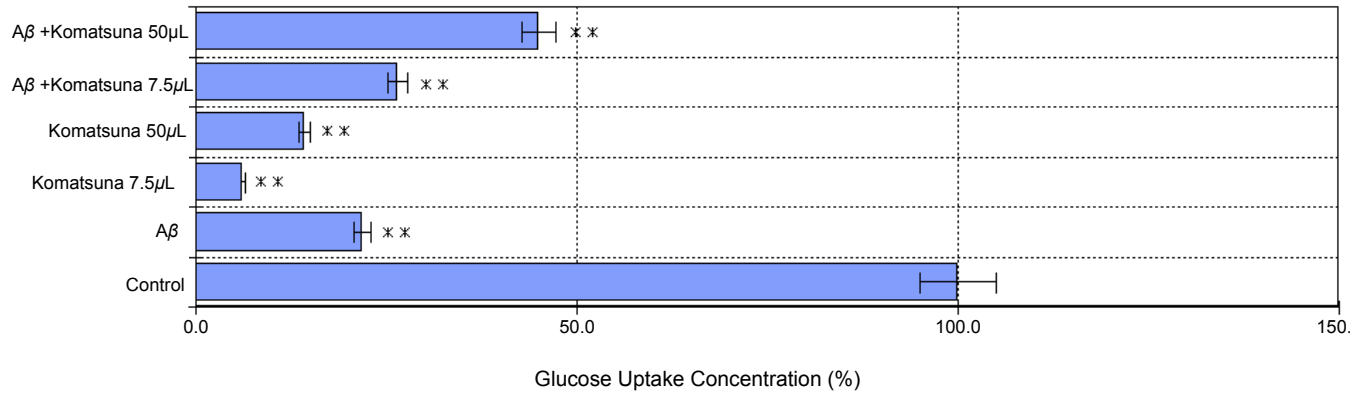

Figure 7: Effect of KSE on glucose level in in culture supernatant of hippocampus neurons.

The cells were incubated to $7.5 \mu \mathrm{L}$ or $50 \mu \mathrm{L}$ KSE concentration for $1 \mathrm{~h}$, and then the cells incubated with or without $10 \mu \mathrm{M} A \beta$ for $48 \mathrm{~h}$. The glucose levels in culture supernatant of hippocampus neurons were determined after the treatment, as described in Materials and Methods. The level of glucose in the supernatant was read at $570 \mathrm{~nm}$ using a microplate spectrophotometer.Values are the mean $\pm \mathrm{SD}$ of three measurements. ${ }^{* *} \mathrm{p}<0.01$ compared with the controls.

control. On the other hand, intracellular ROS accumulation resulting from $A \beta$ treatment was significantly reduced when cells were treated with $\mathrm{KSE}+\mathrm{A} \beta$ as compared to those treated with $\mathrm{A} \beta$ only. Namely, 50 and $7.5 \mu \mathrm{M}$ KSE caused $72 \pm 6.8$ and $85 \pm 9.1 \%$ decreases in oxidative stress levels, respectively. KSE protected HN from oxidative stress in vitro. These results indicate that KSE can inhibit A $\beta$-mediated ROS production in the neurons.

\section{KSE improves glucose uptake by $\mathrm{A} \beta$ in $\mathrm{HN}$}

Preliminary studies showed that $>50 \%$ of the glucose uptake in both hippocampal and cortical cells was blocked by $A \beta$, indicating mediation by a specific glucose transporter [21]. In a one-hour glucose uptake experiment (Figure 6), levels (\%) of glucose uptake were: hippocampal cultures exposed to $10 \mu \mathrm{M} \mathrm{A} \beta, 21.9 \pm 2.29$; hippocampal cultures exposed to $7.5 \mu \mathrm{L}$ KSE, $6.20 \pm 0.575$; hippocampal cultures exposed to $50 \mu \mathrm{L} \mathrm{KSE}, 14.3 \pm 1.15$; hippocampal cultures exposed to $7.5 \mu \mathrm{L} \mathrm{KSE}+10 \mu \mathrm{M} \mathrm{A} \beta, 26.6 \pm 2.30$; hippocampal cultures exposed to $50 \mu \mathrm{L} \mathrm{KSE}+10 \mu \mathrm{M} \mathrm{A} \beta, 45.5 \pm 2.87$. The rate of glucose uptake in 50 $\mu \mathrm{L} \mathrm{KSE}+10 \mu \mathrm{M} \mathrm{A} \beta$ was greater than twofold the rate of uptake in 10 $\mu \mathrm{M} \mathrm{A} \beta$ ( $\mathrm{p}<0.01$; Figure 6 ). In 48 -h glucose level experiment in culture supernatant (Figure 7), levels (\%) of glucose were: hippocampal cultures exposed to $10 \mu \mathrm{M} \mathrm{A} \beta, 252.4 \pm 14.1$; hippocampal cultures exposed to $7.5 \mu \mathrm{L} \mathrm{KSE}, 47.4 \pm 2.35$; hippocampal cultures exposed to $50 \mu \mathrm{L} \mathrm{KSE}$, $18.7 \pm 1.05$; hippocampal cultures exposed to $7.5 \mu \mathrm{L} \mathrm{KSE}+10 \mu \mathrm{M} \mathrm{A} \beta$, $33.0 \pm 3.53$; hippocampal cultures exposed to $50 \mu \mathrm{L} \mathrm{KSE}+10 \mu \mathrm{M} \mathrm{A} \beta$, $36.0 \pm 3.68$. The extent of inhibition of glucose transport in cultures exposed to $10 \mu \mathrm{M} \mathrm{A} \beta$ was $78 \%$ in hippocampal cells (Figure 6). On the one hand, in $48 \mathrm{~h}$ of exposure to $\mathrm{A} \beta$, the rate of decrease in glucose transport slowed considerably (Figure 7). Impairment of glucose transport in cultures exposed to $\mathrm{A} \beta$ preceded cell degeneration; glucose uptake decreased by approximately 2.5 times that of the control during a $48 \mathrm{~h}$ exposure to $\mathrm{A} \beta$ (Figure 7). Exposure of cultures to increasing concentrations of KSE resulted in concentration-dependent increases in the rate of uptake of glucose in both hippocampal cultures exposed to KSE alone and hippocampal cultures exposed to KSE+ A $\beta$ (Figure 6).

\section{Discussion}

In this study, KSE inhibited the toxicity of $\mathrm{A} \beta$, and we proved that it had the potential to protect cells. As a result of having examined modifications to $\mathrm{A} \beta$ by SDS-polyacrylamide gel electrophoresis in 16 samples of edible plant seed, we decided to focus on KSE which showed the most remarkable results (Figure 1). In addition, two different concentrations of KSE inhibited A $\beta$ (1-42)-induced cell death (Figure 2). Therefore, we examined the cell death inhibition mechanism of KSE.

The full understanding of the pathogenesis of $\mathrm{AD}$ has remained elusive, and more evidences are confirming that $\mathrm{AD}$ is a disease with numerous genetic and environmental contributing factors. It has been proposed that a chemical process known as glycation may contribute to both extensive protein cross-linking and oxidative stress in $\mathrm{AD}$ [22]. Glycation is the reaction of a reducing sugar with proteins and lipids, resulting in protein modifications. Glycation reactions are also elevated 
during metabolic dysfunction. Non-enzymatic protein glycation is an endogenous process in which reducing sugars react with amino groups in proteins through a series of Maillard reactions forming reversible Schiff base and Amadori compounds. Wu et al. [23] shows that the Schiff base is oxidized in the first stage of glycation and it easily produces free radicals. These reactions increase the misfolding of the proteins such as $\mathrm{A} \beta$ in $\mathrm{AD}$. Thus, glycation links metabolic dysfunction and may have a causal role in $\mathrm{AD}$.

From statement above, we examined glycation inhibition ability of KSE. In this study, we used the modification model of BSA and D-ribose by Wei et al. [9]. We considered whether KSE might be inhibiting BSA glycation. As a result, we found KSE significantly inhibited glycation of BSA in concentration-dependence (Figure 3a). A similar result was provided about different protein, LAB (Figure $3 \mathrm{~b}$ ). On the other hand, no significant results were evident in BSA or LAB aggregation (Figures $4 \mathrm{a}$ and $4 \mathrm{~b}$ ). KSE had the ability to inhibit glycation, but not the ability to inhibit aggregation of the protein. In other words, reactions with protein and sugar were inhibited by KSE, but KSE did not inhibit aggregation of the cross-linked structure producing protein. The following thing is considered as one thought. It is thought likely that in the stage before protein is modified by sugar, KSE binds to the protein, and KSE disturbs protein modification by sugar. In other words, we propose that the sugar-protein binding site may also be the binding site for the KSEprotein and that KSE may compete with D-ribose.

The process of BSA glycation is triggered by the production of an irreversible heterologous by-product. Adisakwattana et al. [24] reports that cinnamic acid and its derivatives control the carbonyl formation of protein, when they coexist with BSA and fructose, and that they control the oxidation of thiol. The cinnamic acid is distributed over the plant kingdom including the seed widely. Therefore, the cinnamic acid is more likely to be included in KSE. As for the result of 10-day incubation under the coexistence of BSA and D-ribose (Figure 3a), KSE is thought to have produced the result that contributed to the carbonyl formation of protein and oxidation inhibition of thiol, as cinnamic acid controlled the reaction. Glycation and the formation of AGEs can be called the characteristics of diabetes exposed to hyperglycosemic states. Therefore, these inhibitions are pathologically important. Because we have shown it is possible that KSE compete with sugar in protein modification, KSE may contribute to a meaningful delay in the pathological progress such as $\mathrm{AD}$.

In Figure 5, 50 and $7.5 \mu \mathrm{M}$ KSE caused 72 and $85 \%$ decreases in $\mathrm{A} \beta$-mediated ROS levels, respectively. In other words, intracellular ROS level (an important indicator of cell death) examination showed that KSE suppressed intracellular ROS. On the other hand, KSE is a proven radical scavenger. $\mathrm{IC}_{50}$ by the DPPH radical method was $21.22 \mathrm{mg} /$ $\mathrm{mL}$, and total phenolic content was $1.8 \pm 0.17 \mathrm{mg}$ of chlorogenic acid equiv/g [20]. In the experiments in which $\mathrm{KSE}(7.5$ and $50 \mu \mathrm{L})$ treatment was used on cells without $A \beta$, intracellular ROS was not increased in a dose-dependent manner (Figure 5). As for this, KSE might produce a moderate ROS-producing level. However, in cell treatments in which $\mathrm{A} \beta$ was present, KSE showed concentration-dependency. This showed $\mathrm{A} \beta$ caused a high ROS-producing level. However, this may be due to KSE effectively controlling ROS production. In other words, KSE acted as a radical scavenger, and it suggested that KSE could control an increase of intracellular ROS caused by $A \beta$. From the statement above, it is supposed that KSE contributed to the inhibition of cell death caused by $\mathrm{A} \beta$.

Prapong et al. reported that $A \beta$ has been shown to impair glucose uptake in cultured hippocampal neurons and shortens their survival time. $A \beta$ appears to inhibit neuronal glucose uptake by activating Gs-coupled receptors and the cAMP-PKA system [25]. Therefore, we examined the possible contribution of KSE to improving glucose uptake inhibited by $A \beta$. A $\beta$ alone significantly inhibited the uptake of glucose (Figure 7). On the other hand, in the case of coexistence of $A \beta$ and KSE $50 \mu \mathrm{L}$, the glucose uptake level was revived to approximately seven times that of $A \beta$ alone. Similarly, in the case of $A \beta$ and KSE 7.5 $\mu \mathrm{L}$ coexistence (Figure 7 ), the level was improved to approximately eight times. On the other hand, in the one-hour glucose uptake experiment, the following result was provided in Figure 6. In the case of coexistence of $A \beta$ and KSE $50 \mu \mathrm{L}$, the glucose uptake level was revived to approximately twice that of $A \beta$ alone. However, in the case of $A \beta$ and KSE 7.5 $\mu \mathrm{L}$ co-existence, no significant increase in effect was seen. Because the cells increased in well enough (Figure 2), it is thought that this is because uptake of further glucose was not necessary.

Yao et al. showed that the Ginkgo biloba extract EGb 761 rescues the PC12 neuronal cells from $A \beta$-induced cell death by inhibiting the formation of $A \beta$-derived diffusible neurotoxic ligands [26]. Addition of the extract of Ginkgo biloba leaves, EGb 761 together with the $A \beta$ protein prevented, in a dose-dependent manner, the $\mathrm{A} \beta$-induced free radical production and cell death. These results indicate that the terpenoid and flavonoid constituents of EGb 761 are responsible for rescuing the neuronal cells from $A \beta$-induced cell death; their mechanism of action being distinct of their antioxidant properties. Because pre- and posttreatment with EGb 761 did not protect the cells from $A \beta$-induced neurotoxicity, they examined whether EGb 761 interacts directly with $\mathrm{A} \beta$. In vitro reconstitution studies demonstrated that $\mathrm{EGb} 761$ inhibits the formation of $A \beta$-derived diffusible neurotoxic soluble ligands, suggested to be involved in the pathogenesis of AD. Ajibade reported that the phytochemical screening revealed the presence of saponins, tannins, terpenes, alkaloids, flavonoids, carbohydrates, and cardiac glycosides in the methanol extract of the seeds of moringaoleifera [27]. Because KSE was more likely to include a terpenoid and a flavonoid, by the mechanism that was similar to the Ginkgo biloba extract, KSE might show the action that was similar to the Ginkgo biloba extract.

In conclusion, KSE inhibits $\mathrm{A} \beta$-induced cell death. The supposed results are as follows.

1. KSE reduces the toxicity of $A \beta$ by modifying $A \beta$.

2. KSE improves the inhibition of $A \beta$ glucose uptake thereby modifying A $\beta$.

\section{KSE inhibits ROS in cells produced by A $\beta$.}

The possibility that KSE protects cells was strongly suggested by these results.

\section{Acknowledgments}

This work was supported by JSPS KAKENHI (Grant-in-Aid for Challenging Exploratory Research) Grant Number 24650494.

\section{References}

1. Narasimhan K, Govindasamy M, Gauthaman K, Kamal MA, Abuzenadeh AM, et al. (2013) Diabetes of the Brain: Computational Approaches and Interventional Strategies. CNS NeurolDisord Drug Targets.

2. Mehla J, Chauhan BC2, Chauhan NB1 (2014) Experimental induction of type 2 diabetes in aging-accelerated mice triggered Alzheimer-like pathology and memory deficits. J Alzheimers Dis 39: 145-162.

3. Mahboobi H, Golmirzaei J, Gan SH, Jalalian M, Jalalian M1 (2013) Humanin A Possible Linkage between Alzheimer's Disease and Type 2 Diabetes. CNS NeurolDisord Drug Targets

4. Carvalho C, Machado N, Mota PC, Correia SC, Cardoso S, et al. (2013) Type 
Citation: Okada Y, Okada M (2014) Komatsuna Seed Extracts Protection Against Amyloid B(1-42)-Induced Neuronal Cell Death. J Diabetes Metab 5: 368 doi: $10.4172 / 2155-6156.1000368$

Page 8 of 8

2 diabetic and Alzheimer's disease mice present similar behavioral, cognitive, and vascular anomalies. J Alzheimers Dis 35: 623-635

5. Zhong XM, Hou L, Luo XN, Shi HS, Hu GY, et al. (2013) Alterations of CSF cystatin $C$ levels and their correlations with CSF $\hat{\imath} \hat{l}^{2} 40$ and $\hat{\imath} \hat{l}^{2} 42$ levels in patients with Alzheimer's disease, dementia with lewy bodies and the atrophic form of general paresis. PLoS One 8: e55328.

6. Mattson MP, Chan SL (2003) Neuronal and glial calcium signaling in Alzheimer's disease. Cell Calcium 34: 385-397.

7. Vetter SW, Indurthi VS (2011) Moderate glycation of serum albumin affects folding, stability, and ligand binding. Clin Chim Acta 412: 2105-2116.

8. Oliveira LM, Lages A, Gomes RA, Neves H, Família C, et al. (2011) Insulin glycation by methylglyoxal results in native-like aggregation and inhibition of fibril formation. BMC Biochem 12: 41.

9. Wei Y, Chen L, Chen J, Ge L, He RQ (2009) Rapid glycation with D-ribose induces globular amyloid-like aggregations of BSA with high cytotoxicity to $\mathrm{SH}$ SY5Y cells. BMC Cell Biol 10: 10

10. Yamagishi S, Nakamura K, Inoue H, Kikuchi S, Takeuchi M (2005) Serum or cerebrospinal fluid levels of glyceraldehyde-derived advanced glycation end products (AGEs) may be a promising biomarker for early detection of Alzheimer's disease. Med Hypotheses 64: 1205-1207.

11. Iannuzzi C, Maritato R, Irace G, Sirangelo I (2013) Glycation accelerates fibrillization of the amyloidogenic W7FW14F apomyoglobin. PLoS One 8 : e80768.

12. Yakushev I, Schreckenberger M, Müller MJ, Schermuly I, Cumming $P$, et al. (2011) Functional implications of hippocampal degeneration in early Alzheimer's disease: a combined DTI and PET study. Eur J Nucl Med Mol Imaging 38: 2219-2227.

13. Mattson MP, Pedersen WA, Duan W, Culmsee C, Camandola S (1999) Cellular and molecular mechanisms underlying perturbed energy metabolism and neuronal degeneration in Alzheimer's and Parkinson's diseases. Ann N Y Acad Sci 893: 154-175.

14. Zheng L, Terman A, Hallbeck M, Dehvari N, Cowburn RF, et al. (2011) Macroautophagy-generated increase of lysosomal amyloid beta-protein mediates oxidant-induced apoptosis of cultured neuroblastoma cells. Autophagy 7: 1528-1545.

15. Cai Z, Zhao B, Ratka A (2011) Oxidative stress and $\hat{I}^{2}$-amyloid protein in Alzheimer's disease. Neuromolecular Med 13: 223-250.
16. Zampagni M, Wright $D$, Cascella R, D'Adamio G, Casamenti F, et al. (2012) Novel S-acyl glutathione derivatives prevent amyloid oxidative stress and cholinergic dysfunction in Alzheimer disease models. Free Radic Biol Med 52 1362-1371.

17. Schini-Kerth VB, Auger C, Kim JH, Etienne-Selloum N, Chataigneau T (2010) Nutritional improvement of the endothelial control of vascular tone by polyphenols: role of NO and EDHF. Pflugers Arch 459: 853-862.

18. Khattak KF (2011) Nutrient composition, phenolic content and free radical scavenging activity of some uncommon vegetables of Pakistan. Pak J Pharm Sci 24: 277-283.

19. Qin XY, Cheng Y, Yu LC (2012) Potential protection of green tea polyphenols against intracellular amyloid beta-induced toxicity on primary cultured prefrontal cortical neurons of rats. Neurosci Lett 513: 170-173.

20. Okada Y, Okada M (2013) Protective effects of plant seed extracts against amyloid $\hat{I}^{2}$-induced neurotoxicity in cultured hippocampal neurons. J Pharm Bioallied Sci 5: 141-147.

21. Mark RJ, Pang Z, Geddes JW, Uchida K, Mattson MP (1997) Amyloid betapeptide impairs glucose transport in hippocampal and cortical neurons: involvement of membrane lipid peroxidation. J Neurosci 17: 1046-1054.

22. Fawver JN, Schall HE, Petrofes Chapa RD, Zhu X, Murray IV (2012) Amyloid-Î metabolite sensing: biochemical linking of glycation modification and misfolding J Alzheimers Dis 30: 63-73.

23. Wu CH, Huang SM, Lin JA, Yen GC (2011) Inhibition of advanced glycationendproduct formation by foodstuffs. Food Funct 2: 224-234.

24. Adisakwattana S, Sompong W, Meeprom A, Ngamukote S, Yibchok-Anun $S$ (2012) Cinnamic Acid and its derivatives inhibit fructose-mediated protein glycation. Int J Mol Sci 13: 1778-1789.

25. Prapong T, Buss J, Hsu WH, Heine P, West Greenlee H, et al. (2002) Amyloid beta-peptide decreases neuronal glucose uptake despite causing increase in GLUT3 mRNA transcription and GLUT3 translocation to the plasma membrane. Exp Neurol 174: 253-258.

26. Yao Z, Drieu K, Papadopoulos V (2001) The Ginkgo biloba extract EGb 761 rescues the PC12 neuronal cells from beta-amyloid-induced cell death by inhibiting the formation of beta-amyloid-derived diffusible neurotoxic ligands. Brain Res 889: 181-190.

27. Ajibade TO, Arowolo R, Olayemi FO (2013) Phytochemical screening and toxicity studies on the methanol extract of the seeds of moringaoleifera. $J$ Complement Integr Med 10. 